\section{Familiarity and attraction to social and nonsocial objects by rats*}

\author{
BIBB LATANÉ, DAVID POOR, and LLOYD SLOAN \\ Ohio State University, Columbus, Ohio 43120
}

Rats were housed alone, in pairs, or with a tennis ball for 10 days before the start of 10 days of testing for attraction to tennis balls or to other rats. Rats were more attracted to other rats than to tennis balls, attraction to both balls and rats increased over days, and housing with either a ball or a rat reduced attraction to that object but not to the other.

Rats are very much attracted to one another, maintaining an average distance between themselves which may be only half that expected by chance (Latané, 1969). Rats are more gregarious in a familiar environment than in an unfamiliar one (Eckman, Meltzer, \& Latané, 1969). Rats are more attracted to one another if they have not encountered another rat recently than if they are housed continuously with another rat (Cappell \& Latané, 1969; Latané, Cappell, \& Joy, 1970).

These three facts pose two questions: Are the relationships described above specifically "social" or would they also apply to a rat's interactions with nonsocial objects? Secondly, to what extent is the social deprivation effect due to specific lack of contact with other rats as opposed to general stimulus deprivation as a result of being housed in isolation?

The present experiment seeks to answer these questions by investigating the above relationships with regard to a nonsocial object as well as to another rat, and by observing whether the effects of differential housing are specific to the housing object or generalize to other objects.

Previous research has shown that rats are more attracted to other rats than to a variety of metal, glass, or plastic objects such as pipe sections, bottles, or toy cars (Latané \& Glass, 1968; Latané \& Werner, 1971). These objects were typically cold, sharp, heavy, or otherwise possibly aversive and were rather difficult to interact with, to play with, or even to move about the field. In the present experiment, rats were allowed to live with or interact with standard tennis balls since they were similar to the rat in color, size, curvature, and texture and can be easily investigated, climbed upon, and rolled about.

* This research was supported by National Science Foundation Grants GS2292 and GS27340. Request reprints from Bibb Latané, 404C West 17 th Avenue, Columbus, Ohio 43210 .
If rats are housed with such a nonsocial plaything, will they tire of it in the same manner as social housing reduces their desire to interact with conspecifics? Further, will the stimulation of living with a nonsocial object affect rats' attraction to a social object? If there is no qualitative distinction between the satisfactions afforded by interaction with social and nonsocial objects, then attraction to the testing object, social or nonsocial, should be inversely proportional to the amount of stimulation received in housing.

METHOD
Having lived for 10 days alone, with a tennis ball, or with another rat, male albino rats were placed in an open field for $5 \mathrm{~min}$ once each day for 10 successive days and observed for evidence of attraction to either another rat or to a tennis ball.

\section{Subjects and Apparatus}

Sixty naive male Sprague-Dawley albino rats, 70 days old, were randomly divided into 30 pairs and assigned to one of three housing conditions: 20 rats (10 pairs) were housed in single cages; 20 rats $(10$ pairs) were housed individually with a tennis ball; and 10 pairs were housed two rats to a cage. Rats were so housed for 10 days prior to and continuously during the experimental testing period of 10 days, with food and water available ad lib.

The apparatus was a circular wooden open field painted flat white, $4 \mathrm{ft}$ in diam and with an 18-in. surrounding wall (Latané, 1969). The floor was marked by a series of concentric circles and radii into 49 numbered locations of equal area and approximately equivalent shape. A $40-\mathrm{W}$ light bulb was hung $2 \mathrm{ft}$ above the center of the floor of the field. Tennis balls were Court "Standard" brand and received only mild damage over the 20 days they remained in the "ball" housing condition cages. Procedure

Rats were observed in the open field for $5 \mathrm{~min}$ a day for 10 successive days. On half the days, rats were observed in pairs with another rat from the same housing condition (not his cagemate). On alternate days, rats were observed individually with a tennis ball (not one used in housing cages) placed several inches from the wall of the field. Each rat pair was observed in each testing condition five times over the 10 days of the experiment.

Es recorded the amount of time the subject rat and test object (rat or ball) were in physical contact. Contact was timed whenever one rat touched the other (or the ball), including vibrissa but excluding exclusively tail-to-tail contact. The average distance between objects was calculated from locations recorded at 10 -sec intervals. The number of consecutive $10-\mathrm{sec}$ intervals in which the rat was in the same location was taken as a measure of immobility or freezing.

The experiment used a 3 by 2 by 5 experimental design. The between-Ss factor was the housing condition. The two within-Ss factors were the experimental testing condition (with another rat or with a ball) and the day of testing.

\section{RESULTS AND DISCUSSION}

Immobility and Defecation

When tested with another rat, rats were more mobile than when tested with a tennis ball, spending only $5 \%$ of their time immobile compared to $9 \%$ $(F=10.2, \mathrm{df}=1,27, \mathrm{p}<.004){ }^{1}$ This result replicates earlier findings (Latané, 1969; Latané \& Glass, 1968). Familiarity with the open field reduced immobility during tests with the tennis ball from $11 \%$ on the first day to $5 \%$ on the last day of testing $(\mathrm{F}=3.76, \mathrm{df}=4,24, \mathrm{p}<.02)$ but did not affect mobility in tests with another rat (interaction $\mathbf{F}=\mathbf{9 . 0}$, $\mathrm{d} \mathbf{f}=4,24, \quad \mathrm{p}<.006)$. Rats rarely defecated.

Rats were very much attracted to each other, spending overall more than $45 \%$ of their time in the open field in direct physical contact, rubbing up against each other, crawling over and under each other, and chasing each other about. Rats were not very much attracted to the tennis ball, spending overall less than $8 \%$ of their time in contact with it. Each of the 30 pairs of rats spent more time with each other than with the ball, and the $F$, with $\mathrm{df}=1,27$, was over 1,100 . Overall, rats stayed significantly closer to the tennis ball ( 21.8 in.) than the 24.5 in. which would be expected by chance (Latané, 1969; $\mathrm{F}=87.7, \mathrm{df}=1,24, \mathrm{p}<.001)$.

With increasing exposure to the open field, rats increased their contact with other rats from $35 \%$ of their time on their first exposure to another rat in the open field to $54 \%$ on their fifth $(\mathrm{F}=17.9, \mathrm{df}=4,24, \mathrm{p}<.001)$. This may reflect the dropping out of 
competing fear and exploratory responses as the field becomes familiar (Eckman, Meltzer, \& Latané, 1969). Rats also showed increased attraction to the tennis ball, from $6 \%$ to $10 \%$ ( $\mathrm{F}=9.4, \mathrm{df}=4,24, \mathrm{p}<.001)$, but this was not as pronounced as that for social attraction (interaction $\mathrm{F}=13.0$, $\mathrm{df}=4,24, \quad \mathrm{p}<.001)$. These results suggest that rats and tennis balls differ greatly in attractiveness for rats but that the attractiveness of each is similarly related to familiarity of the environment.

When tested with another rat, rats housed alone or with a tennis ball spent more time in contact $(51 \%$ and $55 \%$, respectively) than did rats housed in pairs $(29 \%) \quad(F=104.9$, $\mathrm{df}=1,27, \mathrm{p}<.001$ ) and were not different from one another (n.s.). When tested with a tennis ball, rats housed alone or with another rat had higher times (9\% and $8 \%$, respectively) than rats housed with a ball $(5 \%)$ $(\mathrm{F}=24.8, \quad \mathrm{df}=1,27, \quad \mathrm{p}<.001)$ and were not significantly different from each other (n.s.).

Over all Ss, there was no relationship between time spent in contact with the ball and time spent with the rat partner (overall within-cell $r=.08, n . s$.$) . This null relationship was$ also maintained within the two housing groups which encountered the ball only in testing (alone-housed $r=-.05$, housed-with-rat $r=-.28$, both n.s.). For rats housed with balls, however, time in contact with the ball was highly correlated to time in contact with a rat partner $(r=.79$, $\mathrm{p}<.01)$. Prior familiarity with a nonsocial object may render it qualitatively similar to familiar social objects.

It is apparent that attraction to a nonsocial object is reduced by previous familiarity with that type of object, just as attraction to another rat

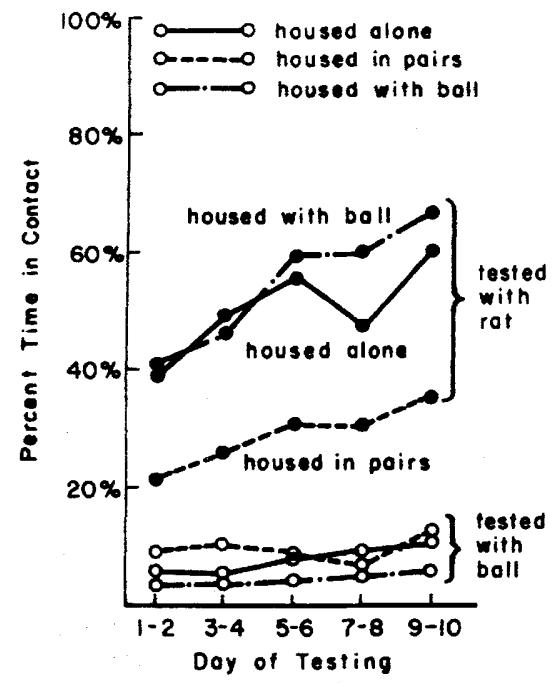

Fig. 1. Time in contact as a function of testing object, day of testing, and housing condition.

is reduced following conspecific housing. This result opposes the prediction by Cairns (1966), Antonitis \& Sher (1952), Zajonc (1969), Scott (1965), and others that mere association should lead to attachment and affiliation and suggests that too much familiarity may lead to a satiation of interest in both social and nonsocial objects.

It is also clear that housing effects were object-specific, that is, that housing a rat with a rat reduced its attraction to other rats (rats were tested with noncagemates) but not to balls, and housing rats with balls reduced attraction to balls but not to rats. Interacting with one type of object doesn't seem to satisfy the need to interact with other types of objects, although it does seem to satisfy the need to interact with other objects of the same type. This implies that distinctions such as those drawn by
Barnett (1963) between social and nonsocial interaction may be functionally justified in that each type of interaction may have its own realm of effect. However, both types of interaction seem to be guided by the same laws.

\section{REFERENCES}

ANTONITIS, J. J., \& SHER, A. J. Social regression in the white rate. Journal of Psychology, 1952, 33, 99-111.

BARNETT, S. S. The rat: A study in behavior. Chicago: Aldine, 1963. Chap. 4 (R at "societies"), pp. 72-99.

CAIRNS, R. B. Attachment behavior of mammals. Psychological Review, 1966 , 73, 409-426.

CAPPELL, H. \& LATANÉ, B. Effects of alcohol and caffeine on the social and emotional behavior of the rat. Quartenly Journal of Studies on Alcohol, 1969, 30, 345-356.

ECKMAN, J., MELTZER, J., \& LATANÉ B. Gregariousness in rats as a function of familiarity of environment. Journal of Personality \& Social Psychology, 1969. 11, 107-114.

FINN, J. B. Multivariate analysis of repeated measures data. Multivariate Behavioral Research, 1969, 4, 391-413.

LATANE, B. Gregariousness and fear in laboratory rats. Journal of Experimental Social Psy chology, 1969, 5, 61-69.

LATANÉ, B., CAPPELL, H., \& JOY, V. Social deprivation, housing density and gregariousness in rats. Journal of Comparative \& Physiological Psychology. $1970,70,221-227$.

LATANÉ, B., \& GLASS, D. C. Social and nonsocial attraction in rats. Journal of Personality \& Social Psychology, 1968, 9, 142-146.

LATANE, B., \& WERNER, C. Social and nonsocial sources of attraction in rats. Psychonomic Science, 1971, 24, 147-148.

SCOTT, J. P. Critical periods in behavioral development. Science, 1965, 138, 949-958.

ZAJONC, R. Attraction, affiliation, and attachment. Symposium on Comparative Social Behavior, Smithsonian Institution, May 1969.

\section{NOTE}

1. Within-S effects and interactions were tested using the multivariate $F$ statistic based on Wilk's Lambda (Finn, 1969). 